\title{
EXPLORING FACTORS INFLUENCING THE Adoption Of ONLINe SHopping With SAudi E- Shops, Female Perspective
}

\author{
Noura Mohammed Aldaej \\ Department of Information Systems, Al-Imam Mohammad Ibn Saud Islamic University \\ (IMSIU), Saudi Arabia
}

\begin{abstract}
Information and communication technology (ICT) is currently the key enabler of most fields and sectors. It contributed to improving the field of commerce by advent, the concept of electronic commerce. The advent of e-commerce contributed to improving the commerce field by enabling customers to conduct their entire business transaction via the internet. Accordingly, e-commerce has become an indicator of the economic growth sought by countries in this digital age. One of the common forms of B2C e-commerce is online shopping in which the customer deals with a website and gets a full shopping experience online. The online shopping environment in Saudi Arabia is expected to grow as a result of the development of ICT, the spread of the Internet, the large proportion of the youth population and the rapid trend of online markets around the world, and in Saudi Arabia in particular. However, it is still immature, and the adoption of online shopping with Saudi e-shops in specific is less than expected. Therefore, this study seeks to explore the factors influencing the adoption of online shopping by females with Saudi e-shops. This study adopted a qualitative methodology, as data were collected by conducting thirty semi-structured interviews with Saudi females and analyzed through applying Thematic Analysis (TA) method using a software tool (NVivo). As a result, the study reported thirteen factors influencing Saudi females to adopt online shopping with Saudi eshops. Those factors were classified under six main themes: products-related factors, logistics-related factors, customer service-related factors, payment-related factors, technology-related factors, and culturerelated factors. Based on the study's findings, the researcher reported the study contributions and future research recommendations in conclusion.
\end{abstract}

\section{KEYWORDS}

ICT, E-commerce, Online shopping, Adoption, E-shops.

\section{INTRODUCTION}

Information and Communication Technology (ICT) is the primary enabler for many sectors in the digital age. Moreover, ICT makes critical changes in all sectors, i.e., (banking, commerce, education, healthcare, manufacturing, and military). ICT has contributed to improving the field of commerce through the advent of the concept of electronic commerce. Through e-commerce, customers will able to conduct the entire business transaction via the internet. E-commerce offers more features compared to conducting the business transaction physically regarding saving time, effort, and cost. It is not just about exchanging products or services; it also about "electronically innovating, communicating, collaborating, and discovering information.”[1].

DOI: $10.5121 /$ ijcsit.2019.11408 
E-commerce is a new model of business that, nowadays, started leading the global economy. Moreover, shifting to this business model is shown by the high numbers of sales through eshoppers around the world [2]. According to Statista, a company specialized in statistical market studies that collect quantitative data, statistics, and information to support business and academics; the leading countries ranked as the highest e-commerce retail sales worldwide between 2014-2019 are China and the United States[3]. E-commerce sales revenue of China amounts to US\$1,568.39 billion, and for the United States, e-commerce sales revenue amounts to US\$ 481.94 billion; followed by the United Kingdom, Japan, Germany, France, South Korea, Canada, Brazil, and Austria. In Asia, e-commerce has begun to compete globally. Malaysia is ranked first based on e-commerce Compound Annual Growth Rate CAGR of 23.8\%, followed by India, with e-commerce CAGR of 23\%[3].

Companies invest in information technology for different reasons; for example, to increase production with low costs, to improve services provided, and to ensure the quality of products [4]. The internet as a technological medium to conduct the business transaction does not guarantee the success of online shopping. Instead, this lies in how to use these technologies to gain a sustainable competitive advantage [5], [6]. Further, with the spread of the internet and the growing numbers of online shopping sites, some of those sites do not meet customer expectations. Measuring the success of online shopping sites do not depend solely on the number of visitors to the site. Instead, it depends on the high percentage of the actual purchase from this site. Understanding customer desires and providing full support services before, during, and after-sales is what makes the user re-visit the site and buy from the same site[6], [7]. An online business needs to focus more on turning visitors into customers. On the other hand, the consumer's decision to adopt and use such technologies provided by companies, i.e., e-shops, depends on many factors. Knowing consumers' motivations and factors affecting their adoption of online shopping will help companies to improve their services and achieve their goals.

Although many countries compete in e-commerce globally by setting up e-shops for online shopping, some are still lagging. In Saudi Arabia, the e-commerce market size reached to US\$3 billion in 2017[8]. The Saudi's Communication and Information Technology Committee (CITC) reported that the percentage of internet users among Saudis is $93 \%$ and approximately $58.5 \%$ of the population is under 30 years [8], [9].

The online shopping environment in Saudi Arabia is expected to grow because of the growing number of internet users and the swift trends of online markets around the world and in Saudi Arabia in particular [10]. However, the adoption of online shopping with Saudi e-shops, in particular, is less than expected [11], [12]. According to the studies conducted by[11], [13]-[15], they asserted that most of Saudis people prefer to shop online from international e-shops rather than (local) Saudi e-shops. Thus, exploring the factors that affect the adoption of online shopping with Saudi e-shops is crucial. Knowing that Saudi females represent the most online shoppers in Saudi Arabia, and thus, they have a significant role in growing and improving this activity [9]. Therefore, understanding the perception of female in specific is essential because the factors that affecting male may not apply or generalize to female. Thus, this study will highlight the perspective of female toward the adoption of online shopping.

\section{LiteratURE REVIEW}

\subsection{E-commerce Overview}

Many researchers have defined the concept of electronic commerce [16]-[23]. Most of them had 
similar definitions in meanings. Furthermore, [22] defined e-commerce as the use of telecommunications networks to conduct business transactions and create relationships with other business. This definition is similar to the definition of [23] which said: "electronic commerce exceeds the sale of goods and services, and expands to include close relationships with customers and other companies." However, we can define e-commerce as an activity that enables business and customers to execute a complete business transaction through the Internet, including activities during and after-sales.

Recently, the volume of e-commerce sales worldwide has increased. According to statistics carried out by[3], the volume of electronic retail sales in 2018 amounted to 2.8 trillion US dollars, and it is expected to reach to 4.48 trillion US dollars by 2021. This significant increase in electronic sales explains the importance of the e-commerce sector and its impacts on the global economy. The growth and integration of information technology through the spread of smartphones and the development of electronic payment systems and delivery options has also contributed to e-commerce growth [21], [24].

According to[25], there are five types of e-commerce based on the category of buyers and sellers, which classified as the following:

$>$ Business to Business (B2B): This type includes the commercial exchange between two companies over the website of one of those two companies or through an intermediary website that offers the products and goods of one company to sold by other companies.

$>$ Business to Customer (B2C): This is a most common type of e-commerce, whereas the company offers its products and goods over usually its website, or through other companies' websites which offer the service of supply and demand to their consumers.

$>$ Business to Employee(B2E): This type target the employee to provide them financial loans of banks and job Insurance offers.

$>$ Business to Governance (B2G): This type includes the commercial exchange between the company and other government sectors for supply, maintenance, and other services through the biddings offered by government sectors.

$>\quad$ Consumer to Consumer $(C 2 C)$ : This type includes the commercial exchange between the individuals with each other through websites which offer the service of supply and demand to enable them to buy and sell from each other.

E-commerce offers several benefits to the business; it constitutes to reducing the cost of hiring physical stores through allowing the business to offer their products and services on an electronic website[20], [26]. It also reduces the cost of workers who serve consumers. What is more, to avoid services differences between the multiple company branches, e-commerce allows creating a unified image of the company to its consumers by providing excellent services through the company website[27]. E-commerce allows the business to streamline their business process, control their operations, and aids business to reach a large segment of consumers [21], [27]. In addition to that, there is no restricted time of sale, where the website operates 24 hours and seven days a week.

On the other hand, e-commerce offers several benefits to consumers as well. It provides the diversity of options between products, sellers, payment choices, the possibility of shopping at 
whatever time and from any place, customizations of products, and making a comparison between available products[2], [21], [27], [28].

\subsection{E-commerce in Saudi Arabia}

In Saudi Arabia, the Saudi government has given importance to the e-commerce sector, whereby many developments and changes have taken place to improve it. In 2007, the Saudi government approved the electronic transactions law to be the legislative base for all electronic transactions in all its applications (government, commercial, health, education, financial, and banking). Therefore, this law fulfills all the requirements of electronic transactions, whether for the government or private sector or individuals [29]. Thus, as a sequence of the evolution of ecommerce, many companies have turned to develop an electronic shop (e-shop) to reach a large segment of customers. The e-shop is an online location (website) for conducting business transactions by the buyers and sellers for products or services.

In 2016, the Ministry of Commerce and Investment (MCI), in cooperation with "Thiqha", a company for business services, launched MAROOF, a website that allows the seller to register his/her e-shop and gives the e-shop an authentication certificate to increase consumers' trust in it [30]. Through MAROOF, the seller can reach a more significant segment of customers as it gives the customers a clear picture of the e-shop products and services. Also, the customer can evaluate the e-shop and write comments about his/her shopping experience on the seller's page.

In 2018, the Saudi government approved the establishment of the Electronic Commerce Council (ECC) headed by MCI and the membership of representatives from government agencies and three representatives from the private sector[31].

In 2019, the Saudi Council of Ministries approved the e-commerce system controlling and organizing e-commerce activities and constructing a legal framework for the e-commerce sector in Saudi Arabia [32].

As a result of the great interest of the Saudi government toward the field of electronic commerce in Saudi Arabia, the value of e-commerce transactions between business and consumers B2C exceeded 29.7 billion SR in 2016[15].

\subsection{Online Shopping Adoption in Saudi Arabia}

Online shopping is a form of purchasing in which the customer deals with an electronic shop and conducts the business transaction online [11]. [12] defined online shopping adoption as "the process when consumers are buying a product from the website of a certain e-retailer and then he/she repeated the visit to the same site for further purchase."Recently, online shopping in Saudi Arabia has grown significantly, wherein the percentage of online shopping adopters increased from $37.3 \%$ in 2016 to $49.9 \%$ in 2018[33]. However, the results of CITC's market survey in 2018 indicated that females accounted for the most significant percentage of online shoppers, with $51.7 \%$ of female shoppers against $48.6 \%$ of male shoppers in 2018.

However, a set of multiple factors resulted in increasing the number of online shopping adopters. Moreover, online shopping is a business activity based on technology. Online shopping is considering as an integrated information system of business processes, technology, and 
individuals (traders, consumers, and other parties involved). Therefore, the study of this activity requires knowledge and awareness of all these involved parties[34]. As individuals are the central part of this system, many previous studies have addressed the factors influncing the online shopping adoption from the consumers' perspective. Table 1 below lists some of the studies that have investigated factors influencing online shopping adoption, both globally and in Saudi Arabia.

Table 1. Works of literature that studied the factors influencing online shopping adoption

\begin{tabular}{|c|c|c|c|}
\hline Author/ year & Title & Approach and sample & Key Results/ findings \\
\hline $\begin{array}{l}\text { Lee, Park, and } \\
\text { Ahn (2001) } \\
{[35]}\end{array}$ & $\begin{array}{l}\text { "On the } \\
\text { Explanation of } \\
\text { Factors } \\
\text { Affecting E- } \\
\text { Commerce } \\
\text { Adoption" }\end{array}$ & $\begin{array}{l}\text { They adopted a quantitative } \\
\text { approach using an online } \\
\text { survey based on the } \\
\text { integration of "Technology } \\
\text { Acceptance Model (TAM) } \\
\text { and Theory of Perceived } \\
\text { Risk (TPR)." The sample } \\
\text { was 176university } \\
\text { students males, and females, } \\
\text { in the U.S. }\end{array}$ & $\begin{array}{l}\text { They found that: "Perceived } \\
\text { ease of use, Perceived } \\
\text { usefulness, the Perceived risk } \\
\text { with products/services, and } \\
\text { Perceived risk in the context of } \\
\text { online transaction" are the } \\
\text { factors affecting consumers' } \\
\text { adoption of e-commerce. }\end{array}$ \\
\hline $\begin{array}{l}\text { Yulihasri, } \\
\text { Islam, and } \\
\text { Daud (2011) } \\
\text { [36] }\end{array}$ & $\begin{array}{lr}\text { "Factors } & \text { that } \\
\text { Influence } & \\
\text { Customers' } \\
\text { Buying The } \\
\text { intention of } \\
\text { Shopping } \\
\text { Online." }\end{array}$ & $\begin{array}{l}\text { They adopted a quantitative } \\
\text { approach using the survey } \\
\text { questionnaire based on } \\
\text { "(TAM) and the theory of } \\
\text { reasoned action (TRA)." The } \\
\text { sample was } 300 \text { students of a } \\
\text { higher learning institution in } \\
\text { Penang, Malaysia. }\end{array}$ & $\begin{array}{l}\text { They found that: } \\
\text { "Compatibility, usefulness, ease } \\
\text { of use, and security" were the } \\
\text { most significant factors that } \\
\text { influence students for online } \\
\text { shopping in Malaysia. }\end{array}$ \\
\hline $\begin{array}{l}\text { Clemes, Gan, } \\
\text { and } \\
\text { Zhang(2014) } \\
\text { [37] }\end{array}$ & $\begin{array}{l}\text { "An Empirical } \\
\text { Analysis of } \\
\text { Online } \\
\text { Shopping } \\
\text { Adoption in } \\
\text { Beijing, China" }\end{array}$ & $\begin{array}{l}\text { They adopted a quantitative } \\
\text { approach using an online } \\
\text { survey. The sample was } 435 \\
\text { respondents, males, and } \\
\text { females, in Beijing. }\end{array}$ & $\begin{array}{l}\text { They found that: "Risk, } \\
\text { Consumer resources, The } \\
\text { quality of service, Subjective } \\
\text { norms, Product variety, } \\
\text { Convenience, and Website } \\
\text { factors" are all factors affecting } \\
\text { consumers' adoption of online } \\
\text { shopping in China. }\end{array}$ \\
\hline $\begin{array}{l}\text { Thang, Thi, } \\
\text { and Huong } \\
\text { (2017) } \\
{[38]}\end{array}$ & $\begin{array}{l}\text { "Factors } \\
\text { Influencing } \\
\text { Online } \\
\text { Shopping } \\
\text { Intention: An } \\
\text { Extension of } \\
\text { The } \\
\text { Technology } \\
\text { Acceptance } \\
\text { Model" }\end{array}$ & $\begin{array}{l}\text { They adopted a quantitative } \\
\text { approach using an online } \\
\text { survey based on "the } \\
\text { extended TAM." The sample } \\
\text { was } 423 \\
\text { male and female respondents } \\
\text { in Vietnam. }\end{array}$ & $\begin{array}{l}\text { They found that: "Perceived } \\
\text { usefulness, Perceived ease of } \\
\text { use, and Trust" had a positive } \\
\text { impact on consumers' online } \\
\text { shopping intention. However, } \\
\text { Perceived risk negatively } \\
\text { impact consumers' online } \\
\text { shopping intention. }\end{array}$ \\
\hline
\end{tabular}




\begin{tabular}{|c|c|c|c|}
\hline $\begin{array}{l}\text { Al-Maghrabi } \\
\text { and } \\
\text { Dennis(2011) } \\
{[13]}\end{array}$ & $\begin{array}{l}\text { "What drives } \\
\text { consumers" } \\
\text { Continues } \\
\text { Intention to E- } \\
\text { shopping." }\end{array}$ & $\begin{array}{l}\text { They adopted a quantitative } \\
\text { approach using an online } \\
\text { survey based on the } \\
\text { integration of "revised TAM } \\
\text { and Expectation } \\
\text { Confirmation Theory } \\
\text { (ECT)." The sample was } 465 \\
\text { male and female respondents } \\
\text { In Saudi Arabia. }\end{array}$ & $\begin{array}{l}\text { They found that: "Perceived } \\
\text { usefulness, Enjoyment, Social } \\
\text { pressure" are determinants of } \\
\text { online shopping in Saudi } \\
\text { Arabia. }\end{array}$ \\
\hline $\begin{array}{l}\text { Alsharif } \\
(2013) \\
{[2]}\end{array}$ & $\begin{array}{l}\text { "Investigating } \\
\text { the Factors } \\
\text { Affecting } \\
\text { Online } \\
\text { Shopping } \\
\text { Adoption in } \\
\text { Saudi Arabia." }\end{array}$ & $\begin{array}{l}\text { He adopted a quantitative } \\
\text { approach using an online } \\
\text { survey that adopted "a } \\
\text { Unified Theory of } \\
\text { Acceptance and Uses } \\
\text { Technology (UTAUT)." The } \\
\text { sample was 472 male and } \\
\text { female respondents. }\end{array}$ & $\begin{array}{l}\text { He found that: "Performance } \\
\text { expectancy, Effort Expectancy, } \\
\text { Social influence, Attitude } \\
\text { toward online shopping, } \\
\text { Anxiety, Self-efficiency, and } \\
\text { facilitating conditions" are the } \\
\text { factors that have a direct effect } \\
\text { on online shopping intention. }\end{array}$ \\
\hline $\begin{array}{l}\text { Khalil(2014) } \\
\text { [39] }\end{array}$ & $\begin{array}{l}\text { "Factors } \\
\text { affecting the } \\
\text { consumer's } \\
\text { attitudes on } \\
\text { online } \\
\text { shopping in } \\
\text { Saudi Arabia." }\end{array}$ & $\begin{array}{l}\text { She adopted a quantitative } \\
\text { approach using an online } \\
\text { survey. The sample was } 210 \\
\text { of staff and students of } \\
\text { different universities and the } \\
\text { general public in Saudi } \\
\text { Arabia. }\end{array}$ & $\begin{array}{l}\text { She found that: "Security and } \\
\text { Privacy" are the top concern for } \\
\text { the purchasers and "Price, } \\
\text { Trust, Convenience, and the } \\
\text { recommendations" are the } \\
\text { factors affecting consumers to } \\
\text { shop online in Saudi Arabia. }\end{array}$ \\
\hline
\end{tabular}

Given the above listed studies, we noticed that most of them had used different technology acceptance models and theories, i.e., "Theory of Reasoned Action (TRA), Unified Theory of Acceptance and Use Technology (UTAUT) and Technology Acceptance Model (TAM)" [2], [13], [35], [36], [38]. Despite the high impact of the models' constructs on the user's behavior toward the adoption of technology, we believe that, with the spread of technology, consumers behavior has become changed toward the adoption of technology, i.e., online shopping. Moreover, consumers have become affected by different factors. Thus, understanding the consumer perception toward online shopping adoption without prior expectation will help us discover several factors resulted from the changed consumer behavior and obtain greater depth in that regard. Accordingly, this study seeks to fill this gap in the literature by giving the participants a free space to explain their perspective by adopting the qualitative approach.

\section{MeThOdology}

This study is qualitative; as it is purpose is to explore the factors influencing the adoption of online shopping by Saudi females with Saudi e-shops. Moreover, the qualitative approach is suitable for the researches that aim at exploring, investigating, or understanding the phenomenon under study [40]. Accordingly, the researcher seeks to achieve this through interaction with females, talk with them, and give them enough space to explain their perspective. Therefore, the researcher is considered a primary data collection instrument. From this, it is obvious to us that the nature of the data to be collected is qualitative. Consequently, the researcher conducted indepth semi-structured interviews with a sample of Saudi females to understand the meanings of the issue from the study participants themselves. A semi-structured interview allows the researcher to deeply understand the participants' perceptions of the phenomenon under study [40]. Accordingly, a sample of Saudi female aged from twenty years and above, who have at least 
two years of experience in online shopping, and shop at least once a month from multiple e-shops (Saudi and non-Saudi e-shops), was recruited in this study as they will be informative and have sufficient experience about the study subject.

Since the study sample is Saudi females, the sample was selected from the university as it is the place where the required sample can easily accessible. Further, data collection was carried out at one of the Saudi government universities in Al-Kharj city (Prince Sattam bin Abdul Aziz University) at the Faculty of Science and Humanities. Thus, we interviewed twenty Saudi females who matched the sample selection criteria and accepted voluntary participating in the current study.

Also, to reach the qualified sample on a broader range, we expanded the scope of data collection by designing an electronic questions form and shared the link on one of the social networking websites (Twitter). As a result, we received ten responses. Thus, we conducted thirty semistructured interviews with Saudi females.

For analyzing the data gathered from the interviews, we adopted a Thematic Analysis (TA) method to analyze the research responses. TA is a systematic method used to find patterns and themes within qualitative data [41]. Moreover, TA is one of the methods used in the analysis of qualitative data where the researcher categorizes the data and assigns them to specific themes or categories, then explains and interprets them to find the answer/s to the research question/s. Thus, we adopted Braun and Clarke's [45] six phases of doing thematic analysis:

Phase 1: Familiarizing Yourself with the Data

Phase 2: Generating Initial Codes

Phase 3: Searching for Themes

Phase 4: Reviewing Potential Themes

Phase 5: Defining and Naming Themes

Phase 6: Producing the Report

\section{FINDINGS AND DISCUSSION}

Based on the analysis of the interviews conducted with Saudi females, we explored thirteen factors affecting Saudi females to adopt online shopping with Saudi e-shops. We classified those factors under six main themes which were ordered based on their priority from the highest to the lowest as stated by the participants: Products-related factors; Logistics-related factors; Customer service-related factors; Payment-related factors; Technology-related factors and Culture-related factors. The following sections will present an explanation and discussion of each theme.

\subsection{Factors Influencing the Adoption of Online Shopping by Saudi Females with Saudi E-Shops}

\subsubsection{Product-Related Factors}

The participants were concerned about some of the product's features when they shop online. Moreover, they asserted that the most significant factor that drives them to shop online is the need for a product with specific features. This category encompassed three factors related to the product as raised by the participants: product price; product quality; and product variety. 
For the product price factor, the researcher found that it attracted great interest from the participants. The high product price made most of the participants reluctant in adopting online shopping with Saudi e-shops. Indeed, consumers tend to utilize online shopping if it will offer to them features not offered in traditional shopping. One of those features, then, is the lower product prices. The consumer today has become more aware, as we noted from the study's sample, that, if she does not find the offer that fits her desires and meets her expectations, she will look for other alternatives that do. There is high competition between companies and businesses in the online shopping environment, which is becoming a challenge for companies to meet the consumers' needs and expectations. However, understanding consumer behavior is one of the most significant factors that businesses need to consider in order to increase the purchasing power from their eshops. Accordingly, companies and businesses have to understand their customers more, know their desires, motivations, and their challenges that govern the decision of purchase adoption from certain e-shops. With the recent development and proliferation of e-shops, the low product price is becoming a competitive advantage for the e-retailer. Thus, consumers' adoption behavior of online shopping is becoming selective.

Moreover, today's consumers are familiar with using technology to satisfy their needs. Therefore, other non-technological factors need to be taken into consideration when switching to technological activities. It is increasingly necessary to meet the customers' requirements from traditional shopping in an online shopping environment as a feature in attracting consumers.

The participants were also concerned about the product quality factor more when they shop online. They described the product as being of high quality if it is authentic, matches the image displayed on the e-shop and is free of any defect/damage. It can sometimes negatively affect their online shopping adoption with Saudi e-shops. As it is known, in online shopping activity, the consumer cannot check the product quality by touch or smell, so that the product quality remains a concern for most of them. As such, the issue of trust emerged from the participants' responses regarding product quality.

Moreover, some of the participants agreed that they were afraid of buying some products online. Nevertheless, they would change their decision to buy those products if a trusted e-shop offered them. Accordingly, a business needs to build trust with their consumers. Trust, therefore, will motivate consumers to overcome their concerns about product quality.

The participants were also attracted to e-shops offering a variety of products. Further, product variety is a factor that influenced the participants positively to adopt online shopping with Saudi e-shops. Interestingly, the participants who lived in a city where there were a limited number of shops offering high-quality brands were more influenced by the product variety factor to adopt online shopping. Indeed, offering a variety of products affords the consumer a wide range of options, which helps in meeting their needs. However, we can interpret this interest in product variety by the fact that females usually prefer to buy many products that fit each other, such as a dress, a bag, and shoes. Therefore, they want to find all these products in one e-shop.

\subsubsection{Logistics-Related Factors}

The participants mentioned some issues related to the logistics process in an online shopping context. Further, the logistics are "the process of planning, implementing and controlling the efficient, effective flow and storage of goods, services, and related information from the point of origin to the point of consumption to confirming the customer requirement"[42]. The participants mentioned two primary logistics-related factors: shipment prices and delivery time. 
For the shipping prices factor, the participants raised the issue of high shipping prices as the factor that makes them not prefer to buy from some of the Saudi e-shops. It all depends on the shipping company that the e-shop uses. Sometimes, and for the low-cost products, the shipping is usually not free, especially for companies that set a specific spend in order to obtain for free shipping. Knowing the financial ability of the targeted consumers is useful in choosing the transport partner. The online shopper, usually, looks at the total price (the product, shipping, and delivery) and, therefore, if he/she feels that the price is high; accordingly he/she will be reluctant to buy. However, allowing the consumer to choose the appropriate shipping option by contracting with more than one shipping company is a feasible solution to resolve this issue. Accordingly, even if the product is low in price, if the shipping cost is high, it will negatively affect the consumers' purchasing decision.

For the delivery time, the participants defined it as the time taken after the shipment arrives until the customer receives it. However, most of the participants who shopped from Saudi e-shops agreed that all provided fast delivery time. As mentioned by some participants, in the case of unexpected events or if the participant needed the product in a short time, the fast delivery time becomes the first feature that drives them to shop from a specific e-shop. Thus, fast delivery time is considered as an advantage that should be exploited by the local e-shops specifically. Having product warehouses in the same region and dealing with fast shipping companies is a success factor for many local e-shops.

\subsubsection{Customer Service-Related Factors}

The participants mentioned issues related to the quality of services provided by the e-shop customer service staff to the e-shop customers. They highlighted two factors related to customer service: response time and after-sales service.

The participants defined response time as the time taken after the customer's inquiry until he/she received the response. They agreed that a quick response from the customer service employee to their inquiries made them comfortable and increased their trust in the e-shop. On the other hand, they also mentioned their interest in the quality of services provided. The reason behind consumers' interest in this factor may be due to the current lifestyle, as the speed factor has become a necessity for doing many activities. Further, no one prefers to wait, especially with the availability of many alternative options and services offered by competitors. We note that a quick response gives the customer a sense of comfort and safety. However, quick response time is not only what the participants care about, but also the quality of the service provided is essential.

Also, the after-sales services - a support service offered after fulfillment of the order - provided by the customer service staff significantly influenced the participants. Mainly, after-sales services include assurance, upgrade, repair and maintenance service, training on the use of the product, money-back guarantees, or replacement in the event of product damage or defects. Based on the participants' statements about this factor, superior after-sales service creates a sense of comfort, satisfaction toward the e-shop, and makes them feel that their inquiries are being given the company's attention and care. The after-sales service is perhaps much more important than the sale itself because it drives the customer to repeat the purchase from the same e-shop. Conversely, if the after-sales service provided by the e-shop is below the level that the customer is looking for, he/she may decide not to repeat the purchase from that e-shop. 


\subsubsection{Payment-Related Factors}

The participants were concerned about the available payment options when they shop online. Moreover, they mentioned some payment options that motivate them to shop from Saudi e-shops. These preferred payment options are Cash On Delivery and MADA payment.

Most of the participants who preferred to shop from Saudi e-shops showed a desire to pay after they received their shipment. However, their motivation toward COD payment option was different. Some of them said that the COD option protected their rights as it ensured that their shipment had arrived. On the other hand, some of them did not have a credit card for online payment. Most of the females who did not have a credit card were those who were still university students as they did not have an independent income. However, some of the participated females justified their unwillingness to own a credit card because of their concerns about security issues, such as stealing their credit card data.

Accordingly, for those females who did not have a credit card, they showed their willingness to use their MADA debit card for online payment, as all of them had such card. Further, the Saudi Arabian Monetary Agency (SAMA) decided to allow all banks to start activating MADA bank cards (debit cards) as a payment option for online transactions on April $1^{\text {st }}$, 2018. This decision was made to promote e-payment culture in Saudi society. Moreover, MADA cardholders can now make the payment for their online purchases from local and non-local e-shops safely without the need to extract a credit card such as Visa, MasterCard, or others. The participants, however, mentioned their successful shopping experiences using their debit card to pay online. On top of that, we could note the new consumer behavior toward technology adoption. Further, the behavior of consumers is affected by the recent technological revolution. As most activities become technology-based, i.e., shopping, consumers become more interested and willing to utilize the technological innovations that help to perform their activities.

\subsubsection{Technology-Related Factors}

The participants were interested in some technological features related to the e-shop. They mentioned two technological factors: ease of use and e-shop design/appearance.

The participants preferred e-shops which are easy to navigate and browse, and show a clear order of steps. However, all the participants who adopted online shopping with Saudi e-shops agreed that it was easy to perform. Indeed, the ease of use of the e-shop is a significant factor, as the participants differed in their choice of best platform (using an e-shop's website or an e-shop's application on Smartphones) according to the easiest one. Furthermore, the ease of access to products, the ease of browsing, navigation between pages, and the ease of order steps are the main factors that drive visitors to buy from the e-shop. Also, if the e-shop is complex to use, the visitor will leave it.

Interestingly, some of the participated females showed their interest in the e-shop design and appearance. Accordingly, if the e-shop has high-quality product images, more product descriptions, and consistent colors, it will attract them to shop from it. We can say that the e-shop design and appearance is the factor that adds aesthetics and enjoyment to consumers' online shopping experience. This aesthetic design, in turn, creates a sense of pleasure and loyalty between the consumer and that e-shop. The e-shop design, also, may reflect the seriousness and 
transparency of the business to their customer, if it has a section for the company history, as mentioned by some participants.

\subsubsection{Culture-Related Factors}

Culture, as defined by [43, p. 4], is "the collective programming of the mind which distinguishes the members of one group or category of people from one another." The participating Saudi females asserted that two factors influenced them to adopt online shopping with Saudi e-shops, which were both related to Saudi culture: Saudi female transportation issues and socio-cultural context effect.

For the Saudi female transportation issues factor, we noted that, since women's driving is not yet common in Saudi Arabia, the issues related to outside activities motivated some of the female participants to adopt online shopping with Saudi e-shops. As a result, they preferred to use online services to overcome some of their transportation constraints. Interestingly, the participants living in cities where there are no malls for selling international brands considered online shopping as a necessary and excellent option to meet their needs for specific products.

The other factor that motivated some of the participants to adopt online shopping with specific Saudi e-shops was the socio-cultural context effect. Moreover, some of the participants said that the motivation that led them to buy from a particular e-shop was praise from their cousins, friends, or others. Although they had a long online shopping experience, they believed the favorable impression of their relatives about a specific e-shop to be a sign of trust, so that they trusted the e-shop more when others praised it. Accordingly, they preferred to ask their cousins and friends or search for the e-shop on social media sites before the actual buying. This perspective seems evident since Saudi society is dominated by a collectivist culture [44]. Furthermore, the members of a society dominated by a collectivist culture are influenced by the opinion of the majority; they follow the group thinking in different fields, including the adoption of technology directed by others. Therefore, understanding the culture of online shoppers is crucial as it interprets how they think and, accordingly, specifies their behavior.

\section{CONCLUSION}

As countries move toward the digital economy and take advantage of ICT's development, ecommerce will become one of the primary revenue resources. Recently, e-commerce has become an indicator of the economic growth sought by countries. However, in light of the promising opportunities enjoyed by Saudi Arabia in the development of ICT, the spread of the Internet, and the large proportion of the youth population, e-commerce in Saudi Arabia has an excellent opportunity to grow. Online shopping is one of the popular forms of B2C e-commerce, and the consumer adoption of this electronic activity is the main engine for its development. Accordingly, the purpose of this study was to explore the factors influencing the adoption of online shopping by Saudi females with Saudi e-shops. Accordingly, the study reported thirteen factors influencing Saudi females when adopting online shopping with Saudi e-shops. The factors were classified under six main themes: products-related factors, logistics-related factors, customer service-related factors, payment-related factors, technology-related factors, and culture-related factors. This study's findings could help to enrich the IS literature, particularly in the e-commerce field, with the essential factors influencing the adoption of online shopping by females with Saudi e-shops and how these factors were affected by the context in which the researcher studied them. Also, eshops owners could benefit from the study's findings to improve their services. The study's 
findings also will help the decision-makers in Saudi Arabia as they shed light on the current status of e-commerce and Saudi e-shops from the customers' perspective. As for future research, it is interesting to examine those factors in another context in other developing countries to understand the differences and similarities in cross-contexts. Also, since online shopping includes other parties (e-shops owners or business), it is valuable to conduct research that studies their perspective about the Saudi market, the challenges they face and what may limit their development.

\section{ACKNOWLEDGMENTS}

First of all, thanksgiving to Allah for his mercy, blessing, guidance, and care that have accompanied me throughout this work. Thanks to Allah, who helped me and enabled me to accomplish this work. I would like to give a special thanks to my advisor Prof. Abdul Rauf Baig for his valuable support and continuance guidance throughout this work.

\section{REFERENCES}

[1] E. Turban, J. Outland, D. King, J. K. Lee, and T. P. Liang, Electronic Commerce 2018: A Managerial and Social Networks Perspective. Springer, 2017.

[2] F. Alsharif, "Investigating the Factors Affecting Online Shopping Adoption in Saudi Arabia," De Montfort University, 2013.

[3] Statista, "Retail e-commerce sales worldwide from 2014 to 2021 (in billion U.S. dollars)," Statista, 2019. [Online]. Available: https://www.statista.com/statistics/379046/worldwide-retail-ecommerce-sales/.

[4] A. L. Lederer, D. J. Maupin, M. P. Sena, and Y. Zhuang, "Role of ease of use, usefulness, and attitude in the prediction of worldwide web usage," Proc. ACM SIGCPR Conf., no. New York, NY, United States, pp. 195-204, 1998.

[5] K. Atchariyachanvanich, H. Okada, and N. Sonehara, "Critical Success Factors of Internet Shopping: The Case of Japan," in International Conference on E-Business and Telecommunications, 2007, p. 12.

[6] M. L. R. Varela, A. F. Araújo, G. G. Vieira, V. K. Manupati, and K. Manoj, "Integrated framework based on critical success factors for e-Commerce," J. Inf. Syst. Eng. Manag., vol. 2, no. 1, p. 9, 2017.

[7] N. Suntornpithug, Z. W. Todorovic, and D. L. Sherrell, "Revisiting the concept of person interactivity through social psychology and social telepresence theory," Int. J. Electron. Bus., vol. 8, no. 1, 2010.

[8] Statista, "Global retail e-commerce market size 2014-2021 I Statista," Statista, 2017. [Online]. Available: https://www.statista.com/statistics/379046/worldwide-retail-e-commerce-sales/.

[9] CITC, “KSA ICT Indicators End of Q4 2018,” 2018.

[10] A. A. Garatli, "WHAT ARE THE NECESSARY SKILLS FOR LEADING AN ONLINE BUSINESS IN SAUDI ARABIA?" ProQuest LLC, 2014.

[11] S. Aljarboa, "Online Shopping in Saudi Arabia: Opportunities and Challenges," Int. J. Manag. Value Supply Chain., vol. 7, no. 4, pp. 01-15, 2016. 
International Journal of Computer Science \& Information Technology (IJCSIT) Vol 11, No 4, August 2019

[12] R. Y. Alsharief, "Saudi Consumers Attitudes Towards Online Shopping,” Int. J. Online, Mark., vol. 7, no. 1, pp. 16-36, 2017.

[13] T. Al-Maghrabi and C. Dennis, "What drives consumers' continuance intention to e-shopping? Conceptual framework and managerial implications in the case of Saudi Arabia," Int. J. Retail Distrib. Manag., vol. 39, no. 12, pp. 899-926, 2011.

[14] R. AlGhamdi, "Diffusion of the Adoption of Online Retailing in Saudi Arabia Diffusion of the Adoption of Online Retailing in Saudi Arabia Rayed Abdullah AlGhamdi," no. June 2014.

[15] CITC, "E-Commerce in Saudi Arabia," 2017.

[16] R. A. Alghamdi, "Diffusion of the Adoption of Online Retailing in Saudi Arabia," no. July 2012.

[17] Z. Bauboniene and G. Guleviciute, "E-Commerce Factors Influencing Consumers' Online Shopping Decision," Soc. Technol., vol. 5, no. 1, pp. 74-81, 2015.

[18] W. H. Delone and E. R. Mclean, "Measuring e-Commerce Success: Applying the DeLone \& McLean Information Systems Success Model,’ Int. J. Electron. Commer., vol. 9, no. 1, 2004.

[19] Y. Eri, M. Aminul Islam, and K. A. Ku Daud, "Factors that Influence Customers' Buying Intention on Shopping Online,”Int. J. Mark. Stud., vol. 3, no. 1, pp. 128-139, 2011.

[20] C. Liu and K. P. Arnett, "Exploring the factors associated with Web site success in the context of electronic commerce," Inf. Manag., vol. 38, no. 1, pp. 23-33, 2000.

[21] T. Mesenbourg, "Measuring the digital economy," 2001.

[22] R. Mostaghel, "Customer Satisfaction: service quality in online purchasing in Iran,” 2006.

[23] Y. TIAN and C. STEWART, History of e-commerce. Electronic Commerce: Concepts, Methodologies, Tools, and Applications. 2007.

[24] G. L. Lohse and P. Spiller, "Electronic shopping,” Commun. ACM, vol. 41, no. 7, pp. 81-87, 1998.

[25] A. Manzoor, E-Commerce: An Introduction. LAP LAMBERT Academic Publishing, 2010.

[26] P. Mandal, "Inter-country Analysis of E-Business,” J. Glob. Inf. Technol. Manag., vol. 7, no. 2, 2004.

[27] G. Ontario, "E-COMMERCE : Purchasing and selling online,” E-bus. Toolkit, p. 1, 2013.

[28] H. N. Siddiqui, "Investigation of intention to use e-commerce in the Arab countries: A comparison of self-efficacy, usefulness, culture, gender, and socioeconomic status in Saudi Arabia and the United Arab Emirates.," 2008.

[29] Yesser, "e-Government Regulations and by-laws," Yesser, 2007. [Online]. Available: https://www.yesser.gov.sa/EN/mechanismsandregulations/regulations/pages/e-

transactions_law.aspx.

[30] MCI, “MAROOF’ AN INITIATIVE TO SUPPORT E-COMMERCE IN THE KINGDOM,” Ministry of Commerce and Investment, 2016. [Online]. Available:

https://mci.gov.sa/en/mediacenter/news/pages/17-04-16-01.aspx. 
International Journal of Computer Science \& Information Technology (IJCSIT) Vol 11, No 4, August 2019

[31] ECC, “About The Council,” E-commerce Council, 2018. [Online]. Available:

https://ecc.gov.sa/aboutus/Pages/default.aspx.

[32] MCI, "E-commerce System,” 2019. [Online]. Available:

https://mci.gov.sa/ar/ECC/Pages/default.aspx.

[33] CITC, "Communications Commission The percentage of online shopping in the Kingdom increased to $49.9 \%$ by the end of 2018," Communications and Information Technology Commission, 2019. [Online]. Available:

https://www.citc.gov.sa/ar/mediacenter/pressreleases/Pages/2019031901.aspx.

[34] Ammenwerth, Iller, and Mahler, "IT-adoption and the interaction of task, technology, and individuals: a fit framework and a case study," MC Med. informatics Decis. Mak., vol. 6, no. 1, 2006.

[35] D. Lee, J. Park, and J.-H. Ahn, "On the explanation of factors affecting e-commerce adoption," ICIS 2001 Proc., vol. 14, 2001.

[36] Yulihasri, M. Islam, and K. Daud, "Factors that Influence Customers ' Buying Intention on Shopping Online,” Int. J. Mark. Stud., vol. 3, no. 1, pp. 128-139, 2011.

[37] M. Clemes, C. Gan, and J. Zhang, “An Empirical Analysis of Online Shopping Adoption in Beijing, China,” J. Retail. Consum. Serv., vol. 21, no. 3, pp. 364-375, 2014.

[38] H. N. Thang, N. Thi, and L. Huong, "Factors Influencing Online Shopping Intention : an Extension of the Technology Acceptance," vol. 126, no. 5, pp. 47-58, 2017.

[39] N. Khalil, "Factors affecting the consumer's attitudes on online shopping in Saudi Arabia," Int. J. Sci. Res. Publ., vol. 4, no. 1, pp. 2250-3153, 2014.

[40] J. Creswell, Research Design: Qualitative, Quantitative, and Mixed Methods Approaches. 2014.

[41] V. Braun and V. Clarke, "Thematic Analysis," in APA Handbook of Research Methods in Psychology, the American Psychological Association, 2012, pp. 57-71.

[42] B. Finch, Operations now: Supply chain profitability and performance, 3rd ed. Boston : McGrawHill/Irwin, 2008.

[43] G. Hofstede, "Culture as Mental Programming," in Cultures and Organizations: Software for the Mind, 2nd ed., McGraw Hill Professional, 2004, p. 4.

[44] M. Almousa and D. Brosdahl, "Online apparel purchasing: a cultural comparison of Saudi Arabian and U.S. consumers,” J. Int. Bus. Cult. Stud., vol. 8, no. 1, 2014. 